\title{
Cellullar Plasticity and Dedifferentiation: A Link Between Cancer Stem Cells, Hypoxia, Cell Injury, and Inflammation
}

\author{
Andi Yasmin Wijaya1, I Ketut Sudiana ${ }^{1,2}$, Ami Ashariati Prayogo ${ }^{1,3}$ \\ ${ }^{1}$ Faculty of Medicine, Airlangga University, Surabaya, Indonesia \\ ${ }^{2}$ Pathological Anatomy Department, Faculty of Medicine, Airlangga University, Surabaya, \\ Indonesia \\ ${ }^{3}$ Hematology and Medical Oncology Division, Department of Internal Medicine, Dr.Soetomo \\ Teaching Hospital, Surabaya, Indonesia \\ *Corresponding author: andiyw.fkua@gmail.com
}

\begin{abstract}
Cellular plasticity is the concept of bidirectional dynamics change cells differentiation degree which involved in the regeneration, repair and tissue turnover along the organism livespan. Cellular plasticity and dedifferentiation process are well documented in the discovery of iPCSs by introducing several transcriptional factors known as Yamanaka factor to terminally differentiated somatic cells and reverted into pluripotent state as the ESCs. iPSCs are able to exhibit ESCs differentiation potential which could produce ectodermic, mesodermic, and endodermic cell lineage. In tumour biology, the tumour plasticity also have a similar regulation and play an imporant role for maintaining tumour integrity and survival, particularly in maintaining CSCs population. Various study of cellular plasticity regulation has shown that various factors are involved, in example hypoxia, cell injury, and inflammation. Cells respond to hypoxia, cell injury, and inflammation by chemoattractant which attract repair cells to homing towards injured sites. The homing mechanism of stem cells involved EMT to facilitates migration of stem cells towards injured sites, thus leading to tissue regeneration. On the other hand, cancer metastasis also showed a connection with EMT process. EMT which showed a change in cell properties are linked to dedifferentiation and hypoxia response. Hypoxia condition has been known to preserve and both normal stem cells and CSCsstemness. HIF which protected from degradation in hypoxia condition interact with DNA by binding to HRE. HRE activation trigger transcription of numerous signalling protein which involved in stemness, cell proliferation and survival. Therefore it is concluded that cell injury, hypoxia, and inflammation could programmed cells to undergo dedifferentiation process and involved in EMT regulations. CSCs which resides insides heterogeneous tumour cells population are though to be dynamicly regulate itself in the quietscent and active state through dedifferentiation like the normal stem cells. Understanding how CSCs regulates its active an quietscent state dynamics could provide an important information for novel CSCs targeted therapy development.
\end{abstract}

Keywords : dedifferentiatio,; hypoxia, inflammation, neoplastic stem cells, stem cells 


\section{INTRODUCTION}

Stem cells study development has shown an substantial advancement in the recent years; an important example is the demonstration of cellular plasticity (Yamanaka, 2010). Production of iPSCs (induced pluripotent stem cells) is one of the evidence of cellular plasticity and the dynamics of bidirectional cells differentiation degree (Takahashi and Yamanaka, 2006). iPSCs could revolutionary change and minimize or even substitute usage of ESC (embryonic stem cells), which undoubtedly draws an immense bioethical issues (Yamanaka, 2010). In cancer biology it is known that stem cells play a strategic position and identification of cancer stem cells provide more unknown to be revealed (Magee et al., 2012).Stem cell ability to maintain its population and preserve regeneration ability along organism whole lifetime tightly depend on asymmetric mitosis to maintain stem cells pool. Asymmetric mitosis produce original stem cells phenotype population and able to establish cells with differentiation ability to various lineage descendant (Gómez-López et al., 2014). Cancer stem cells (CSCs) theory propose an asymmetric hierarchical models in cancer population to explain heterogenic cancer cell population (Maugeri-Saccà et al., 2012). Cancer cells metabolism and intercellular interaction show a different role between each cells which imitatecomplex organ and tissue biology (Tetteh et al., 2015). Hypoxia condition in cellular level are known to provide advantages in stem cells cultivation, mainly for maintaining cell stemness, preventing differentiation, and protecting from cell senescence (Abdollahi et al., 2011). Cell ability to adapt in hypoxia condition involves various molecular signalling and caused many change in cellular metabolism. HIF (hypoxia inducible factor) is one of the important protein which responsible for hypoxia coping mechanism (Tsai et al., 2011). Several growth factors and signalling molecules are known to be related with HIF signalling, such as EGF and bFGF which were also involved in inflammation (Calvani et al., 2006; Sporn and Roberts, 1986; Wang et al., 2012). Therefore supplementation of particular signalling molecules showed that cells are able to mimic hypoxia response (Khong et al., 2013; Shi et al., 2005). Increase of stemness marker were able to be observed in stem cells, adult cells, and cancer cells population (Han et al., 2008; Wang et al., 2014). EMT-like process also able to be stimulated by growth factor supplementation which mimicking metastasis-like process (Borovski et al., 2011; Vermeulen et al., 2010). In line with increasing stemness, dedifferentiated cells showed an increased survivability by upregulated efflux pump and DNA repair ability (Abdullah and Chow, 2013; Blanpain et al., 2011). High survivability and extensive efflux pump phenotype are known to be owned by normal stem cells and CSCs (Moitra, 2015).A holistic approach in understanding tumour biology and eventually will produce an effective treatment strategy for cancer. 


\section{Inflammation and Regeneration}

Inflammation process is a natural response against injury. Inside living organism the process comprised of various immunologic and cellular events, which generally aims to clear the cause of inflammation and to repair damaged tissue (Gurtner et al., 2008). Inflammation is generally initiated through stimulation of innate immune receptor by damage associated molecular pattern (DAMP) and pathogen associated molecular pattern (PAMP) (Newton and Dixit, 2012). Damage to cell results in discharge of intracellular component such as nucleic acid, mitochondrial component and intracellular protein, which are all referred as DAMP (Anders and Schaefer, 2014). Toll-like receptor (TLR) binding activates nuclear factor kappaB (NF-kB), a central inflammatory transcription factor. NF- $\kappa \mathrm{B}$ triggers expression of cytokines and cellular activation within immunologic pathway. Hypoxia condition is postulated to also activate $\mathrm{NF}-\kappa \mathrm{B}$ by another pathway involving hypoxia inducible factor (HIF) (Ignazio and Rocha, 2016).

As inflammation is related to tissue damage, tissue regeneration is also related to inflammatory process. Transforming growth factor beta (TGF $\beta)$, epidermal growth factor (EGF), vascular endothelial growth factor (VEGF), insulin-like growth factor (IGF), interleukin 6 (IL-6), interleukin 1 beta (IL-1 $\beta$ ) and other stimulating factor play major role in modulating involved progenitor cells (Aurora and
Olson, 2015; Discher et al., 2010). These stimulating factors are secreted by macrophage which infiltrate the inflammation site as part of the inflammatory process (Aurora and Olson, 2015).

Regeneration is the ability to recover and replace the damaged and senescent organ or tissue with new cells and tissue (Walter et al., 1996). Regeneration capability of living organism varies in among different species (Sánchez Alvarado, 2012). Flat worm planaria have the ability to recover from complete horizontal axis separation (Sánchez Alvarado, 2012). Amphibian such as salamander exhibit the high regeneration potential and able to regenerate amputated limbs(Kragl et al., 2009). Mammals regeneration potential are more limited to several specialized tissues(Li and Clevers, 2010; Riehle et al., 2011). As in human, liver regeneration ability are greater than the kidney (Mason and Dunnill, 2008a). Different capacity of organ regeneration could affected by the microenvironmental and each organ stem cell niche and reserve, in example the regenerative ability and process in the liver are different if compared to wound regeneration (Poss, 2010).

\section{Regenerative ability of organs are} affected by the age of an individual, it has been proven that usage of aged individual serum for culturing stem cells impaired the expression of stemness marker (Carlson and Conboy, 2007).Telomerase activity as gene integrity keeper could be one of responsible factor of regeneration limit, because shortening of 
telomere is associated with impaired regeneration ability (Satyanarayana et al., 2003). Accumulation of DNA damage in the aged individual by DNA repair defect, shortening of telomere, and free radicals damage tend to be one of the process of degeneration and aging (Von Figura et al., 2009).

Stem cells are known to play an important role in regeneration (Falanga, 2012).Stem cells respond to the damaged or senescent tissues by proliferating and sending several cytokines and chemokines to recruit more stem cells and regenerating the damaged or senescent tissues (Gnecchi et al., 2008). There are several theory about stem cells role in regeneration, damaged tissues replacement and differentiation or stimulating native site unipotent or oligopotent stem cells (progenitors) to regenerate itself(Baraniak and McDevitt, 2010). Stem cells labelling before delivered to research subject body are performed for observing stem cells behaviour in tissue regeneration(Srivastava and Bulte, 2014). Cells labelling methods such as GFP gene labelling, BrdU labelling, and PKH labelling are utilized(Tao et al., 2014). However despite the diverse cells labelling methods, there are several limitation. Limitation on the label signal lowering due to cells cleavage, label leakage, and the toxicity of labelling substance are found(Zhang, 2009). The results of the experiment are often contradicting, eventually lead into debate and controversy (Hocking and Gibran, 2010). Further research using better cell labelling methods are needed to precisely confirm stem cells role in regeneration.

Stem cells could help regeneration by homing mechanism to the injured sites, this mechanism were able to be observed both in the stem cells which resides in tissues and circulating stem cells (Raveh-Amit et al., 2013). Injured organ tend to release several chemokines and cytokines as a 'call for help' signal, this signal then received by diverse cells on human bodies (Fong et al., 2011). Immunologic cells such as neutrophil and macrophages, adipocytes, and stem cells (Gurtner et al., 2008; Shook et al., 2016). These response could lead into regeneration or repair signalling networks. The final endproducts of tissues repair are scar tissues or perfect regeneration of damaged tissues, a demonstration of different endproducts could easily noticed in liver cirrhosis and liver regeneration (Wiemann et al., 2002). Study of regeneration process and its utilization finally resulting in a novel field in medicine known as regenerative medicine (Mason and Dunnill, 2008b).

Regenerative medicine focused on the study and application of organ and tissue regenerative ability to regain normal organ function and physiology after injury (Mason and Dunnill, 2008b). Stem cells and growth factors are the main modality and focus in regenerative medicine development and application. Usage of stem cells for therapeutic purpose are often known as cell based therapy, on the other hand the approach of regeneration stimulation using 
growth factors is known as growth factor based therapy (Fong et al., 2011; Gnecchi et al., 2008). Administration of stem cell in cell based therapy offer a complete complex stem cell regenerative factors from living stem cells, yet this approach could potentially bring risk of malignancy (Halme and Kessler, 2006). Therefore non-cell based regenerative therapy approach are developed in hope to reduce the risk of malignancy. However even without the administration of living cells towards patient

\section{Stem cells}

Stem cells are the population of cell which not exhibit specific phenotype from well differentiated adult tissue(Alvarez et al., 2012). Stem cells have the ability to produce the differentiated cells and tissues through the differentiation process, however the differentiation capability of stem cells are limited(Jaenisch and Young, 2008). Stem cells could be divided based on the differentiation capacity: pluripotent stem cells which could differentiat into any lineage of cells and tissue, multipotent stem cells which have the ability to produce specific lineage of differentiated cells, more limited differentiaion ability oligopotent stem cells and eventually the unipotent stem cells which ony capable to differentiated ito one specific differentiated tissues (Jaenisch and Young, 2008).In the regeneration and healing, stem cells play an important role. Stem cells also able to maintaincell self-renewal ability through system, the risk of iatrogenic malignancy are still not absolutely removed which could be observed in the contraindication of growth factor administration in cancer high risk population (Bodnar, 2013). Inseparable understanding and consideration from both cancer biology and stem cell biology point of view are needed for further regenerative medicine development, especially for patient safety concern and optimizaiton of therapeutic potency (Halme and Kessler, 2006).

asymmetric mitosis for maintaining stem cells pool.

Asymmetric mitosis, which is extensively studied in Drosophila,display that intrinsic mechanism and extrinsic mechanism involved in regulating asymmetric cellular division(Liu et al., 2016). Intrinsic factor which involved in cellular polarity are the uneven distribution of intracellular self-renewal factorwhich produce a different polarity in cells(Wen and Zhang, 2018). Extrinsic factor which decide assymetric mitosis is the interaction of cells with the surrounding niche, a different polarity in cell niche could influence course of mitosis. The pole of cells which in contact with stem cell niche is going to maintain its stemness and self renew ability. In contras for the opposite pole, the produced daughter eclls will lose the self renewal ability and gave rise to differentiated cells(Gómez-López et al., 2014). The long livespan of stem cells could be explained by this theory. However, because of stem cells long 
livespan the cellular damage which happen from the beginning of stem cell existence are accumulated. Therefore accumulated damage could affect stem cells condition and produce a mutated stem cells population which slowly

\section{Cancer Stem Cells (CSCs)}

Cancer are the dieases which caused by malignant unregulated cells proliferation which could lead into mortality and morbidity(Xu et al., 2017). Cancer are originated from genetic defected cells which have mutation on the oncogene which regulate proliferation or tumor suppressor gene which responsible for cell death signalling(Seyfried, 2012). Cancer as a malignancy could occur in the solid tissue such as breast cancer, pancreatic cancer, bone cancer, and skin cancer, andnon solid tissue cancer could manifest as leukemia and lymphoma(Bray et al., 2018). In the recent development, cancer cells population are proven to be heterogenous population. Cancer hierarchy model could explain the heterogenity in cancer population(Bonnet and Dick, 1997). Cancer cells are organized as a hierarchy based on its differentiation degree. Cancer stem cells (CSCs) lies in the apex of cancer hierarchy based on its stemness nature and lack of differentiation phenotypes (Maugeri-Saccà et al., 2012).

\section{Cellular plasticity\& dedifferentiation}

dividing and eventually could lead into malignancy(Ullah and Sun, 2018). This mechanism could describe origin of cancer stem cells.

Cancer stem cells are the malignant cells which have the simiral ability of stem cells (Fillmore and Kuperwasser, 2008; Rantam et al., 2014). CSCs population stemness are manifested in the self-renewal ability, chemotherapy resistant, and radiotherapy resistant phenotype (Maugeri-Saccà et al., 2012).CSCs firstly identified in the acute myeloid leukemia (AML) (Bonnet and Dick, 1997). Breast CSCs as the first solid tumour CSCs are then discovered in 2003 (Al-Hajj et al., 2003). CSCs existence in all of the cancer type are then well established(Bomken et al., 2010). The existence of cancer stem cells in clinical settings could lead into cancer relapse(Maugeri-Saccà et al., 2012). Cancer relapse are the process of re-emerging cancer population proliferation and progression after post therapy cancer remission, targeting CSCs speceific population strategy could suppress the possibility of cancer relapse (Li et al., 2015).

Cellular plasticity are the concept of bidirectional cellular differentiation, differentiation of various differentiated tissue from stem cells and the reversion of cellular 
stemness from thedifferentiatedcell state (Tetteh et al., 2015). In the regeneration, stem cells activation to stimulate cell migration and regenerative signal were triggered by tissue injury (Gurtner et al., 2008).

As a multicellular organism, every cells in human body have the same genome, but the epigenetic process are the key factor for developing tissue specific functional cells from stem cells (Li et al., 2017). Differentiation are the establishment of tissue mature specific functional cell or tissue from progenitor and stem cells (Khavari et al., 2010). Stem cells undergo complex cellular signalling to activated or inactivated specificset of gene which are needed for tissue specific function (de-Leon and Davidson, 2007).

This process play an important role in the process of regeneration. This concept are proven by the discovery of induced pluripotent stem cells (iPSCs). iPSCs are the differentiated cells which regain its pluripotency by the process of dedifferentiation(Takahashi and Yamanaka, 2006). iPSCs dedifferentiaton or the reversal of cellular clock could be acheved by introducing several growth factor, or known as Yamanaka factor. Yamanaka factor consist of Oct3/4, Sox2, c-Myc, and Klf4, by introducing this factors the terminally differentiated cells could be reverted into the pluripotent state(Takahashi and Yamanaka, 2006). In the in vivo settings this process would involve a complex overlaping network of cell signalling pathways and further study are needed to reveal this complex process.
Although a massive study of signalling pathways profilling are needed to confirm the complete signalling pathways, it has been known that dedifferentiation are linked to the hypoxia, inflammation and response to injury (Jögi et al., 2003; Muz et al., 2014; Nordmann et al., 2017; Wang et al., 2017a).

Hypoxia condition triggered hypoxia response signalling in the stem cells. Hypoxia induced factor-1 alpha subunit are known as unstable protein in the normoxia condition, but for adapting hypoxia environtment HIF-1 $\alpha$ are stabilized and the HIF signalling pathways are activated (Ignazio et al., 2017). HIF signalling pathways could induce cell dedifferentiation (Wang et al., 2017b).

In the inflammation human body secretes various cytokines and chemokines both the antiinflammatory and pro-inflammatory type, with the tendency of pro-inflammatory signalling domination (Cavaillon, 2001). Based from previous study it was proven that there is a connection between the HIF signalling pathways and the inflammatory signalling pathways which involved Nf-kB, STAT3, PI3K, JAK in addition inflammation also cause the tissue environment to produce higher concentration of regeneration growth factors such as EGF, bFGF, and SCF (Lennartsson and Ronnstrand, 2012). Thereforeit leads to the increasing survivability of cells, involving proliferation, apoptotic resistancy, rapid metabolism and detoxification which is corresponding for stem cells high survivability and CSCs apoptosis resistancy. 
Revisiting the regeneration process stem cells repair of the wound there are homing and resident stem cells which play a role (Gurtner et al., 2008). Both resident and homing stem cells are not constantly in active state, instead they can exist in queitscent state which currently are difficult to detect (Raveh-Amit et al., 2013). However the significance of a stem cell existence in regeneration is more crucially marked by selfrenewal ability, assymetric mitosis, and ability to regenerate damaged tissues (Gurtner et al., 2008). Therefore leaving widely used stemness biomarker such as Oct-4, Klf4, SOX2, c-Myc, CD133, and CD44 not as a definitive indicator of stemness, yet these marker still could serve as a relative indicator of degree of cell differentiation (Zhou et al., 2014). Dynamics dedifferentiation, EMT, and MET process in stem cells and CSCs tend to be difficult to assess in the in vivo system.

In in vitro settings it has been generally accepted that the dedifferentiation process could be performed by culturing the cells in the serum free medium supplemented with growth factors such as EGF, bFGF, and B27 supplement mediumor by using hypoxia incubator (Heddleston et al., 2010; Wang et al., 2014). By introducing stem cells and CSCs with dedifferentating growth factors supplementation or hypoxic condition the increase of stemness marker expression and growth kinetics are observed (Ahmed et al., 2016).

Normal human cells, including stem cells in the in vitro culture system exhibit limited ability of cell division and finally suffer from senescence or known as Hayflick limit which linked to telomere length (Hayflick and Moorhead, 1961; Shay and Wright, 2000). Surpassed Hayflick limit could be observed in hypoxia cultured cells and in the cancer cell culture, this ability are though to be linked with HIF-1 $\alpha$ signalling (Gurtner et al., 2008). HIF-1 $\alpha$ have the ability to interact with hTERT (human telomerase active subunit) and increased cell division capability and even able to surpass Hayflick limit (Nishi et al., 2004; Yatabe et al., 2004).

Besides dedifferentiation process EGF, $b$ FGF, and B27 serum free medium are used to be the medium for differentiating stem cells into neuronal lineage, maintaining neurological tumour primary cell culture, and for assessing tumorsphere forming capacity (Maric et al., 2003). Neurological development and cancer niche are predominantly in hypoxia condition (Francis and Wei, 2010). Besides in neurological tumour and development the other solid organs such as breast and liver, especially the solid stromal tissuesalso shown to related in hypoxia condition (Laitala and Erler, 2018). However cell and tissue hypoxia status are relative and could be different from the hypoxia condition in blood circulation, affected by different organs and different location of the organ.

In molecular level EGF and bFGF signalling mechanism are interwinded with HIF signalling complex. HIF-1a which normally degraded in normoxia by PHDs (condition is maintained in hypoxia condition. HIF-1a could 
translocate to nucleus and bind with HIF-1 $\beta$ to produced HIF which will interact with HRE. HRE activation lead to transcription of various signalling molecules including bFGF, bFGF as the signalling molecules also have the ability of autocrine loop which increases HIF-1 $\alpha$ expression thus leading to amplification of bFGF and HIF signalling (Calvani et al., 2006). Activation of HRE also showed increase expression of SCF (stem cell factor) which usually happen in hypoxia condition activated by HIF-1 $\alpha$ (Han et al., 2008). SCF activated c-Kit signalling which eventually lead to downstream activation of numerous signalling cascade such as PI3K, Src family kinase, MAPK, Phospholipase $\mathrm{C}$ and $\mathrm{D}$ signalling which mainly regulates cell survivability (Lennartsson and Ronnstrand, 2012).In this case normal stem cells and CSCs

\section{CONCLUSION}

Hypoxia response signalling which is overlapped with inflammation and regeneration pathways. Inflammation are not solely purposed for an clearance mechanism of pathogen or damaged tissue. The inflammatory process and hypoxia response prepare various factor for regeneration process that affects stem cells, which includes production of regeneration growth factor. The dynamic process of

\section{REFERENCES}

Abdollahi, H., Harris, L.J., Zhang, P., McIlhenny, S., Srinivas, V., Tulenko, T., DiMuzio, P.J., 2011. The Role of showed an activity of autocrine mechanism for maintaining its stemness as well as making an ideal stemness maintaining niche.

Targeting CSCs dedifferentiation process could be adopted as cancer therapy approach. APL (acute promyelocytic leukaemia) differentiation therapy which involved usage of retinoic acid (RA) for induce tumour cells differentiation could eventually induce cell terminal maturation and loss of cancer cells self renewal ability (De Thé, 2018). Differentiated tumour cells showed a more susceptible condition for immune system clearance and restore response to chemotherapy and radiotherapy (Campos et al., 2010; De Thé, 2018). Further research to understand how dedifferentiation occur and programmed could lead to a better and effective cancer therapy development.

regeneration also involved activation of EMT, MET, and dedifferentiation which regulate normal stem cells homing ability and metastasis in cancer.Cancer cells dedifferentiation and CSCs self renewal ability are the source of cancer persistence which responsible for cancer relapse. Understanding CSCs biology is a critical steps for a better and effective cancer therapy development, without overlooking CSCs similarity with normal stem cells.

Hypoxia in Stem Cell Differentiation and Therapeutics. J. Surg. Res. 165, 112-117.

Abdullah, L.N., Chow, E.K.-H., 2013. Mechanisms of chemoresistance in 
cancer stem cells. Clin. Transl. Med. 2, 3.

Ahmed, N.E.M.B., Murakami, M., Kaneko, S., Nakashima, M., 2016. The effects of hypoxia on the stemness properties of human dental pulp stem cells (DPSCs). Sci. Rep. 6, 1-10.

Al-Hajj, M., Wicha, M.S., BenitoHernandez, A., Morrison, S.J., Clarke, M.F., 2003. Prospective identification of tumorigenic breast cancer cells. Proc. Natl. Acad. Sci. U. S. A. 100, 3983 3988.

Alvarez, C. V., Garcia-Lavandeira, M., Garcia-Rendueles, M.E.R., DiazRodriguez, E., Garcia-Rendueles, A.R., Perez-Romero, S., Vila, T.V., Rodrigues, J.S., Lear, P. V., Bravo, S.B., 2012. Defining stem cell types: Understanding the therapeutic potential of ESCs, ASCs, and iPS cells. J. Mol. Endocrinol. 49.

Anders, H.-J., Schaefer, L., 2014. Beyond Tissue Injury-Damage-Associated Molecular Patterns, Toll-Like Receptors, and Inflammasomes Also Drive Regeneration and Fibrosis. J Am Soc Nephrol Jul 25.

Aurora, A.B., Olson, E.N., 2015. Immune Modulation of Stem Cells and Regeneration. Cell Stem Cell. 15, 1425.

Baraniak, P.R., McDevitt, T.C., 2010. Stem cell paracrine actions and tissue regeneration. Regen. Med. 5, 121-143.

Blanpain, C., Mohrin, M., Sotiropoulou, P.A., Passegué, E., 2011. DNA-Damage Response in Tissue-Specific and Cancer Stem Cells. Cell Stem Cell 8, 16-29.

Bodnar, R.J., 2013. Epidermal Growth Factor and Epidermal Growth Factor Receptor: The Yin and Yang in the Treatment of Cutaneous Wounds and Cancer. Adv. wound care 2, 24-29.

Bomken, S., Fišer, K., Heidenreich, O., Vormoor, J., 2010. Understanding the cancer stem cell. Br. J. Cancer 103, 439445.

Bonnet, D., Dick, J.E., 1997. Human acute myeloid leukemia is organized as a hierarchy that originates from a primitive hematopoietic cell. Nat. Med. 3, 730-737.

Borovski, T., De Sousa E Melo, F., Vermeulen, L., Medema, J.P., 2011. Cancer stem cell niche: The place to be. Cancer Res. 71, 634-639.

Bray, F., Ferlay, J., Soerjomataram, I., Siegel, R., Torre, L., Jemal, A., 2018. Global cancer statistics 2018: GLOBOCAN estimates of incidence and mortality worldwide for 36 cancers in 185 countries. CA A J. Clin. 00, 1-31. Calvani, M., Rapisarda, A., Uranchimeg, B., Shoemaker, R.H., Melillo, G., 2006. Hypoxic induction of an HIF-1alphadependent bFGF autocrine loop drives angiogenesis in human endothelial cells. Blood 107, 2705-2712.

Campos, B., Wan, F., Farhadi, M., Ernst, A., Zeppernick, F., Tagscherer, K.E., Ahmadi, R., Lohr, J., Dictus, C., Gdynia, G., Combs, S.E., Goidts, V., Helmke, B.M., Eckstein, V., Roth, W., Beckhove, P., Lichter, P., Unterberg, A., Radlwimmer, B., Herold-Mende, C., 2010. Differentiation Therapy Exerts Antitumor Effects on Stem-like Glioma Cells. Clin. Cancer Res. 16, 2715-2728.

Carlson, M.E., Conboy, I.M., 2007. Loss of stem cell regenerative capacity within aged niches. Aging Cell 6, 371-382.

Cavaillon, J.M., 2001. Pro- versus antiinflammatory cytokines: myth or reality. Cell. Mol. Biol. (Noisy-le-grand). 47, 695-702.

de-Leon, S.B.-T., Davidson, E.H., 2007. Gene Regulation: Gene Control Network in Development. Annu. Rev. Biophys. Biomol. Struct. 36, 191-212.

De Thé, H., 2018. Differentiation therapy revisited. Nat. Rev. Cancer 18, 117- 
127.

Discher, D.E., Mooney, D.J., Zandstra, P.W., 2010. Growth factors, matrices, and forces combine and control stem cells. Science (80-. ). 324, 1673-1677.

Falanga, V., 2012. Stem Cells in Tissue Repair and Regeneration. J. Invest. Dermatol. 132, 1538-1541.

Fillmore, C.M., Kuperwasser, C., 2008. Human breast cancer cell lines contain stem-like cells that self-renew, give rise to phenotypically diverse progeny and survive chemotherapy. Breast Cancer Res 10.

Fong, E.L.S., Chan, C.K., Goodman, S.B., 2011. Stem cell homing in musculoskeletal injury. Biomaterials 32, 395-409.

Francis, K.R., Wei, L., 2010. Human embryonic stem cell neural differentiation and enhanced cell survival promoted by hypoxic preconditioning. Cell Death Dis. 1, e2211.

Gnecchi, M., Zhang, Z., Ni, A., Dzau, V.J., 2008. Paracrine mechanisms in adult stem cell signaling and therapy. Circ. Res. 103, 1204-1219.

Gómez-López, S., Lerner, R.G., Petritsch, C., 2014. Asymmetric cell division of stem and progenitor cells during homeostasis and cancer. Cell. Mol. Life Sci. 71, 575597.

Gurtner, G.C., Werner, S., Barrandon, Y., Longaker, M.T., 2008. Wound repair and regeneration. Nature 453, 314-321.

Halme, D.G., Kessler, D.A., 2006. FDA Regulation of Stem-Cell-Based Therapies. N. Engl. J. Med. 355, 1730 1735.

Han, Z.B., Ren, H., Zhao, H., Chi, Y., Chen, K., Zhou, B., Liu, Y.J., Zhang, L., Xu, B., Liu, B., Yang, R., Han, Z.C., 2008. Hypoxia-inducible factor (HIF)- $1 \alpha$ directly enhances the transcriptional activity of stem cell factor (SCF) in response to hypoxia and epidermal growth factor (EGF). Carcinogenesis 29, 1853-1861.

Hayflick, L., Moorhead, P.S., 1961. The serial cultivation of human diploid cell strains. Exp. Cell Res. 25, 585-621.

Heddleston, J.M., Li, Z., Lathia, J.D., Bao, S., Hjelmeland, A.B., Rich, J.N., 2010. Hypoxia inducible factors in cancer stem cells. Br J Cancer 102.

Hocking, A.M., Gibran, N.S., 2010. Mesenchymal stem cells: paracrine signaling and differentiation during cutaneous wound repair. Exp. Cell Res. 316, 2213-2219.

Ignazio, L.D., Batie, M., Rocha, S., 2017. Hypoxia and Inflammation in Cancer, Focus on HIF and NF- $\kappa$ B. Biomedicines 5,21 .

Ignazio, L.D., Rocha, S., 2016. Hypoxia Induced NF- $\kappa$ B 1-8.

Jaenisch, R., Young, R., 2008. Stem Cells, the Molecular Circuitry of Pluripotency and Nuclear Reprogramming. Cell 132, 567-582.

Jögi, A., Øra, I., Nilsson, H., Poellinger, L., Axelson, H., Påhlman, S., 2003. Hypoxia-induced dedifferentiation in neuroblastoma cells. Cancer Lett. 197, 145-150.

Khavari, D.A., Sen, G.L., Rinn, J.L., 2010. DNA methylation and epigenetic control of cellular differentiation. Cell Cycle 9, 3880-3883.

Khong, T.L., Thairu, N., Larsen, H., Dawson, P.M., Kiriakidis, S., Paleolog, E.M., 2013. Identification of the angiogenic gene signature induced by EGF and hypoxia in colorectal cancer. BMC Cancer 13, 518.

Kragl, M., Knapp, D., Nacu, E., Khattak, S., Maden, M., Epperlein, H.H., Tanaka, E.M., 2009. Cells keep a memory of their tissue origin during axolotl limb regeneration. Nature 460, 60-65.

Laitala, A., Erler, J.T., 2018. Hypoxic 
Signalling in Tumour Stroma. Front. Oncol. 8, 1-13.

Lennartsson, J., Ronnstrand, L., 2012. Stem Cell Factor Receptor/c-Kit: From Basic Science to Clinical Implications. Physiol. Rev. 92, 1619-1649.

Li, L., Clevers, H., 2010. Coexistence of Quiescent and Active Adult Stem Cells in Mammals. Science (80-. ). 327, 542545.

Li, Q., Xue, X., Li, W., Wang, Q., Han, L., Brunson, T., Xu, W., Chambers-Harris, I., Wang, Q., Li, X., Ma, L., Song, Q., 2017. Heterogeneous DNA methylation status in same-cell subpopulations of ovarian cancer tissues. Tumor Biol. 39, 0-7.

Li, Y., Rogoff, H. a, Keates, S., Gao, Y., Murikipudi, S., Mikule, K., Leggett, D., Li, W., Pardee, A.B., Li, C.J., 2015. Suppression of cancer relapse and metastasis by inhibiting cancer stemness. Proc. Natl. Acad. Sci. U. S. A. 112, 1839-1844.

Liu, Y., Singh, S.R., Zeng, X., Zhao, J., Hou, S.X., 2016. The Nuclear Matrix Protein Megator Regulates Stem Cell Asymmetric Division through the Mitotic Checkpoint Complex in Drosophila Testes. PLOS Genet. 11, e1005750.

Magee, J.A., Piskounova, E., Morrison, S.J., 2012. Cancer Stem Cells: Impact, Heterogeneity, and Uncertainty. Cancer Cell 21, 283-296.

Maric, D., Maric, I., Chang, Y.H., Barker, J.L., 2003. Prospective cell sorting of embryonic rat neural stem cells and neuronal and glial progenitors reveals selective effects of basic fibroblast growth factor and epidermal growth factor on self-renewal and differentiation. J.Neurosci. 23, 240 251.

Mason, C., Dunnill, P., 2008a. A brief definition of regenerative medicine.
Regen. Med. 3, 1-5.

Mason, C., Dunnill, P., 2008b. A brief definition of regenerative medicine. Regen. Med. 3, 1-5.

Maugeri-Saccà, M., Bartucci, M., De Maria, R., 2012. DNA damage repair pathways in cancer stem cells. Mol. Cancer Ther. 11, 1627-36.

Moitra, K., 2015. Overcoming Multidrug Resistance in Cancer Stem Cells. Biomed Res. Int. 2015, 1-8.

Muz, B., de la Puente, P., Azab, F., Luderer, M., Azab, A.K., 2014. Hypoxia promotes stem cell-like phenotype in multiple myeloma cells. Blood Cancer J. 4, e262.

Newton, K., Dixit, V.M., 2012. Signaling in Innate Immunity and Inflammation. Cold Spring Harb. Perspect. Biol. 4, a006049-a006049.

Nishi, H., Nakada, T., Kyo, S., Inoue, M., Shay, J.W., Isaka, K., 2004. HypoxiaInducible Factor 1 Mediates Upregulation of Telomerase (hTERT). Mol. Cell. Biol. 24, 6076-6083.

Nordmann, T.M., Dror, E., Schulze, F., Traub, S., Berishvili, E., Barbieux, C., Böni-Schnetzler, M., Donath, M.Y., 2017. The Role of Inflammation in $\beta$ cell Dedifferentiation. Sci. Rep. 7, 1-10.

Poss, K.D., 2010. Advances in understanding tissue regenerative capacity and mechanisms in animals. Nat. Rev. Genet. 11, 710-722.

Rantam, F.A., Ferdiansyah, Purwati, 2014. Stem Cell Mesenchimal, Hematopoetik, dan Model Aplikasi, 2nd ed. Airlangga University Press, Surabaya.

Raveh-Amit, H., Berzsenyi, S., Vas, V., Ye, D., Dinnyes, A., 2013. Tissue resident stem cells: till death do us part. Biogerontology 14, 573-590.

Riehle, K.J., Dan, Y.Y., Campbell, J.S., Fausto, N., 2011. New concepts in liver regeneration. J. Gastroenterol. Hepatol. 26 Suppl 1, 203-212. 
Sánchez Alvarado, A., 2012. Q\&amp;A: What is regeneration, and why look to planarians for answers? BMC Biol. 10, 88.

Satyanarayana, A., Wiemann, S.U., Buer, J., Lauber, J., Dittmar, K.E.J., Wüstefeld, T., Blasco, M.A., Manns, M.P., Rudolph, K.L., 2003. Telomere shortening impairs organ regeneration by inhibiting cell cycle re-entry of a subpopulation of cells. EMBO J. 22, 4003-4013.

Seyfried, T.N., 2012. Cancer as a Metabolic Disease. John Wiley \& Sons, Inc., New Jersey.

Shay, J.W., Wright, W.E., 2000. Hayflick, his limit, and cellular ageing. Nat. Rev. Mol. Cell Biol. 1, 72.

Shi, Y.H., Wang, Y.X., Bingle, L., Gong, L.H., Heng, W.J., Li, Y., Fang, W.G., 2005. In vitro study of HIF-1 activation and VEGF release by bFGF in the T47D breast cancer cell line under normoxic conditions: Involvement of PI-3K/Akt and MEK1/ERK pathways. J. Pathol. 205, 530-536.

Shook, B., Rivera Gonzalez, G., Ebmeier, S., Grisotti, G., Zwick, R., Horsley, V., 2016. The Role of Adipocytes in Tissue Regeneration and Stem Cell Niches. Annu. Rev. Cell Dev. Biol. 32, 609631.

Sporn, M.B., Roberts, A.B., 1986. Peptide growth factors and inflammation, tissue repair, and cancer. J. Clin. Invest. 78, 329-332.

Srivastava, A.K., Bulte, J.W.M., 2014. Seeing stem cells at work in vivo. Stem Cell Rev. 10, 127-144.

Takahashi, K., Yamanaka, S., 2006. Induction of pluripotent stem cells from mouse embryonic and adult fibroblast cultures by defined factors. Cell 126, 663-76.

Tao, R., Sun, T.J., Han, Y.Q., Xu, G., Liu, J., Han, Y.F., 2014. Optimization of in vitro cell labeling methods for human umbilical cord-derived mesenchymal stem cells. Eur. Rev. Med. Pharmacol. Sci. 18, 1127-1134.

Tetteh, P.W., Farin, H.F., Clevers, H., 2015. Plasticity within stem cell hierarchies in mammalian epithelia. Trends Cell Biol. 25, 100-108.

Tsai, C.C., Chen, Y.J., Yew, T.L., Chen, L.L., Wang, J.Y., Chiu, C.H., Hung, S.C., 2011. Hypoxia inhibits senescence and maintains mesenchymal stem cell properties through down-regulation of E2A-p21 by HIF-TWIST. Blood 117, 459-469.

Ullah, M., Sun, Z., 2018. Stem cells and antiaging genes: double-edged sword-do the same job of life extension. Stem Cell Res. Ther. 9, 3.

Vermeulen, L., De Sousa E Melo, F., van der Heijden, M., Cameron, K., de Jong, J.H., Borovski, T., Tuynman, J.B., Todaro, M., Merz, C., Rodermond, H., Sprick, M.R., Kemper, K., Richel, D.J., Stassi, G., Medema, J.P., 2010. Wnt activity defines colon cancer stem cells and is regulated by the microenvironment. Nat. Cell Biol. 12, 468.

Von Figura, G., Hartmann, D., Song, Z., Rudolph, K.L., 2009. Role of telomere dysfunction in aging and its detection by biomarkers. J. Mol. Med. 87, 11651171.

Walter, J.B., Talbot, I.C., Gardner, H.A., et. al., 1996. General Pathology, 7th ed. Churchill Livingstone, New York.

Wang, P., Wan, W., Xiong, S.-L., Feng, H., $\mathrm{Wu}, \mathrm{N} ., 2017 \mathrm{a}$. Cancer stem-like cells can be induced through dedifferentiation under hypoxic conditions in glioma, hepatoma and lung cancer. Cell Death Discov. 3, 16105.

Wang, P., Wan, W., Xiong, S., Wang, J., Zou, D., Lan, C., Yu, S., Liao, B., Feng, H., 
Wu, N., 2017b. HIF $1 \alpha$ regulates glioma chemosensitivity through the transformation between differentiation and dedifferentiation in various oxygen levels. Sci. Rep. 7, 1-16.

Wang, R., Lv, Q., Meng, W., Tan, Q., Zhang, S., Mo, X., Yang, X., 2014. Comparison of mammosphere formation from breast cancer cell lines and primary breast tumors. J. Thorac. Dis. 6, 829-837.

Wang, Y., Roche, O., Xu, C., Moriyama, E.H., Heir, P., Chung, J., Roos, F.C., Chen, Y., Finak, G., Milosevic, M., Wilson, B.C., Teh, B.T., Park, M., Irwin, M.S., Ohh, M., 2012. Hypoxia promotes ligand-independent EGF receptor signaling via hypoxiainducible factor\{ltextendash\}mediated upregulation of caveolin-1. Proc. Natl. Acad. Sci. 109, 4892-4897.

Wen, W., Zhang, M., 2018. Protein Complex Assemblies in Epithelial Cell Polarity and Asymmetric Cell Division. J. Mol. Biol. 430, 3504-3520.

Wiemann, S.U., Satyanarayana, A., Tsahuridu, M., Tillmann, H.L., Zender, L., Klempnauer, J., Flemming, P., Franco, S., Blasco, M.A., MANNS, M.P., RUDOLPH, K.L., 2002.
Hepatocyte telomere shortening and senescence are general markers of human liver cirrhosis. FASEB J. 16, 935-942.

Xu, H., Yu, S., Liu, Q., Yuan, X., Mani, S., Pestell, R.G., Wu, K., 2017. Recent advances of highly selective CDK4/6 inhibitors in breast cancer. J. Hematol. Oncol. 10, 97.

Yamanaka, S., 2010. Patient-Specific Pluripotent Stem Cells Become Even More Accessible. Cell Stem Cell 7, 1-2. Yatabe, N., Kyo, S., Maida, Y., Nishi, H., Nakamura, M., Kanaya, T., Tanaka, M., Isaka, K., Ogawa, S., Inoue, M., 2004. HIF-1-mediated activation of telomerase in cervical cancer cells. Oncogene 23, 3708-3715.

Zhang, Y., 2009. Autologous cell sources for urological applications. In: Drenstedt, J., Atala, A. (Eds.), Biomaterials and Tissue Engineering in Urology. CRC Press, Cambridge, pp. 334-356.

Zhou, Y., Fan, W., Xiao, Y., 2014. The effect of hypoxia on the stemness and differentiation capacity of PDLC and DPC. Biomed Res. Int. 2014. 